\title{
Peroxisome Biogenesis Disorder
}

National Cancer Institute

\section{Source}

National Cancer Institute. Peroxisome Biogenesis Disorder. NCI Thesaurus. Code C155747.

A group of conditions characterized by impairment of peroxisome assembly and metabolic pathways confined to this organelle, caused by mutation(s) in the peroxin (PEX) gene family. Phenotypically, they manifest as Zellweger syndrome (ZS), neonatal adrenoleukodystrophy (NALD), infantile Refsum disease (IRD), and rhizomelic chondrodysplasia punctata (RCDP1), the latter a distinct peroxisome biogenesis disorder phenotype. ZS, NALD, and IRD have multiple complementation groups and form a spectrum of diseases with overlapping features. 